AperTO - Archivio Istituzionale Open Access dell'Università di Torino

\title{
3D-ELECTRICAL RESISTIVITY TOMOGRAPHY MONITORING OF SALT TRANSPORT IN HOMOGENEOUS AND LAYERED SOIL SAMPLES
}

\section{This is the author's manuscript}

Original Citation:

Availability:

This version is available http://hdl.handle.net/2318/93548

since $2015-12-22 T 15: 57: 53 Z$

Published version:

DOI:10.1007/s11440-011-0146-3

Terms of use:

Open Access

Anyone can freely access the full text of works made available as "Open Access". Works made available under a Creative Commons license can be used according to the terms and conditions of said license. Use of all other works requires consent of the right holder (author or publisher) if not exempted from copyright protection by the applicable law. 


\section{3 \\ UNIVERSITÀ DEGLI STUDI DI TORINO}

This is an author version of the contribution published on:

Questa è la versione dell'autore dell'opera:

Acta Geotechnica, Volume 6, Number 4, 195-203, DOI 10.1007/s11440-011-0146-3

The definitive version is available at:

La versione definitiva è disponibile alla URL:

[http://link.springer.com/article/10.1007\%2Fs11440-011-0146-3] 


\title{
3D-Electrical Resistivity Tomography monitoring of salt transport in homogeneous and layered soil samples
}

\author{
Cesare Comina $^{(1)}$, Renato Maria Cosentini ${ }^{(2)}$, Gabriele Della Vecchia ${ }^{(2)}$, Sebastiano Foti ${ }^{(2)}$, \\ Guido Musso * (2) \\ (1) Università di Torino, Torino, Italy \\ (2) Politecnico di Torino, Torino, Italy
}

\author{
Contact details (* corresponding author): \\ Dr. Guido Musso \\ Assistant Professor \\ Dipartimento di Ingegneria Strutturale e Geotecnica, \\ Corso Duca degli Abruzzi, 24 \\ Politecnico di Torino, \\ 10129 - Torino - Italy \\ Fax: +39-011-090-4837 \\ email: guido.musso@polito.it
}

Number of words in the main text: 3100

Number of tables: 2

Number of illustrations: 11 


\section{SYNOPSIS}

Monitoring transport of dissolved substances in soil deposits is particularly relevant where safety is concerned, as in the case of geo-environmental barriers. Geophysical methods are very appealing, since they cover a wide domain, localising possible preferential flow paths and providing reliable links between geophysical quantities and hydrological variables. This paper describes a 3D laboratory application of Electrical Resistivity Tomography (ERT) used to monitor solute transport processes. Dissolution and transport tests on both homogeneous and heterogeneous samples were conducted in an instrumented oedometer cell. ERT was used to create maps of electrical conductivity of the monitored domain at different time intervals and to estimate concentration variations within the interstitial fluid. Comparisons with finite element simulations of the transport processes were performed to check the consistency of the results. Tests confirmed that the technique can monitor salt transport, infer the hydro-chemical behaviour of heterogeneous geomaterials and evaluate the performances of clay barriers.

Keywords: transport; diffusion; advection; soil laboratory testing; electrical resistivity; tomography; monitoring; clay barriers. 


\section{Introduction and background}

The study of transport of dissolved species through natural soils and manmade earth structures is complicated by different phenomena. For example, flaws in environmental barriers made of compacted clays or geosynthetic clay liners (GCL) can cause preferential flow paths for contaminants. Monitoring is then required to track contaminant transport, to locate potential dangerous leakages and to calibrate numerical models through back-analysis.

Direct monitoring through local concentration measurements, e.g. in the laboratory to draw breakthrough curves (e.g. Shackelford and Daniel, 1991) or in situ through periodic sampling of pore fluid within wells (e.g. Freeze and Cherry, 1979), typically concerns a limited number of points in space and time. In situ, additional uncertainties are related to water mixing within the wells and disturbance of soil structure due to probe installation.

Imaging techniques can provide two- or three-dimensional representations of the investigated soil volume at different times. Being non invasive, they do not disturb flow patterns and soil structure. Electrical Resistivity Tomography (ERT) allows the distribution of the electrical conductivity of an investigated domain to be inferred. With respect to other techniques ERT has two main advantages: cost effectiveness and suitability for a wide range of scales, both in the laboratory and in situ. Moreover electrical conductivity can be related to hydrological variables (water content, porosity, solute concentration) on the basis of both empirical and theoretical relationships (for a review see e.g. Santamarina et al., 2001). In situ measurements have been adopted in geophysical prospecting to monitor contaminant flow (e.g. Reynolds, 1997, Müller et al., 2010), showing the complexity of diffusion processes due to the variability of flow and transport in natural environments (Kemna et al., 2002). 
Laboratory applications of ERT have the strong advantage that tests can be performed under known boundary conditions and controlled soil properties so that a direct comparison with numerical simulations is possible. Laboratory experiences have documented the application of 2D ERT to monitor saline diffusion in reconstituted sand samples (Comina et al., 2005; Damasceno et al., 2009) and in an undisturbed soil column (Binley et al., 1996). In these experiments electrical measurements were taken on horizontal planes and information on the 3D diffusion process was therefore limited. Koestel et al. (2008) monitored transport of a tracer, applied as a uniform front, along a soil column through measurements taken by rings of electrodes placed at different heights; 3D inversions of such measurements provided excellent data concerning the migration of solute.

The present work evaluates the capabilities of 3D ERT in monitoring transport of a saline tracer originating from a punctual source. Tests to investigate solute transport in homogeneous and heterogeneous samples have been performed in an oedometer cell (EIT oedometer), which allows spatial and temporal monitoring of electrical and seismic properties under controlled mechanical and hydraulic conditions (Comina et al., 2008) . The same equipment has been used to monitor transient flow events in the unsaturated range (back analysis of these results allowed Cosentini et al.(2012) deriving the water retention properties of non plastic soil samples).

The cell has an internal diameter of $130 \mathrm{~mm}$ and it can host samples with maximum height of $60 \mathrm{~mm}$ : 42 electrodes are placed on the internal boundary of the cell, 16 equallyspaced on the sidewall and 13 on both the top cap and the base. A picture of the cell is reported in Figure 1. Conductivity measurements for tomography require the injection of current at two electrodes, while other pairs of electrodes measure the induced electrical potentials. Different measuring quadruples must be used in order to investigate the 
conductivity distribution in the whole sample. In the present study, about 800 measurements were performed for each tomography (see Comina et al., 2008, for details about the measurement protocol). Differently from the scheme adopted by Koestel et al. (2008), measurements are taken not only along the lateral side of the sample, but also vertically, particularly in the centre of the sample where the resolution of the inverse problem is poor. All the measurements are then used to reconstruct the electrical conductivity field within the sample, using an inversion technique based on a least-squares algorithm with Tikhonov regularization. The soil is modelled with a finite element mesh and the electrical conductivity of each element is estimated in order to obtain the final reconstruction (Borsic et al., 2005). Acquisition of a single set of measurements can be performed in a few minutes.

\section{Dissolution and transport tests}

Tests have been performed to monitor solute transport in both homogeneous (Test 1) and heterogeneous (Tests 2 and 3) samples (Figure 2). Few grams of $\mathrm{NaCl}$ were placed at a location on the top of the specimen (Figure 2-a). Salt grains were then submerged with distilled water to induce dissolution and subsequent diffusion towards the specimen. Electrical measurements were carried out for three days, approximately every 30 minutes, to monitor movement of the solute. In all the tests the measured average electrical conductivity of the sample increased during approximately the first 400 minutes and then remained constant. This time interval is likely related to the complete dissolution of the $\mathrm{NaCl}$ grains, whose rate is anyway controlled by the associated transport mechanism (see Appelo \& Postma, 1993). Measurements at subsequent times can then be associated to solute redistribution within the specimen, occurring at a constant global amount of salt. 
The geometry of the experiment could lead to unstable flow conditions and to fingering, due to the fact that the denser miscible fluid (saline water) is initially above the lighter one. The adequateness of electrical techniques in general, and ERT in particular, to detect viscous and saline fingering has been documented in the literature (see e.g. Liu and Holtz, 2004 and Van Dam et al., 2009).

\subsection{Homogeneous sand specimens}

Test 1 was performed on a homogeneous saturated specimen of Ticino Sand, a mono-granular siliceous sand with well rounded particles with average size of $0.5 \mathrm{~mm}$. The sample was prepared by moist-tamping at porosity $\phi=0.40$. The height of the sample was $4 \mathrm{~cm}$.

Since neither porosity nor degree of saturation changed during the test, the measured variations of the local electrical conductivity can be directly related to local variations of water salinity. The initial electrical conductivity of the pore fluid, measured with a conductimeter, was $\sigma_{w 0}=1.76 \mathrm{mS} / \mathrm{cm}$. The initial average electrical conductivity of the sample, as given by a tomographic reconstruction, was $\sigma_{0}=0.35 \mathrm{mS} / \mathrm{cm}$.

In Figure 3 reconstructions taken during the first 90 minutes of testing are reported. The images show the elements of the mesh whose conductivity exceeded a threshold value of 2 $\mathrm{mS} / \mathrm{cm}$. They are representative of the volume experiencing an increase of solute concentration at different times. Images indicate that the solute was spreading with an almost hemispherical pattern, consistently with the homogeneity of the sample.

\subsection{Layered sand - clay specimens}

Two tests were performed on layered specimens, prepared by placing between two layers of Ticino sand a $1 \mathrm{~cm}$ thick clay layer (Figure 2-b) of reconstituted Spes White China Clay Kaolinite (Test 2) or of reconstituted Scanzano Clay (Test 3). The Spes White China Clay has 
liquid limit $w_{L}=50 \%$, plasticity index $P I=23 \%$ and activity $A=0.28$. Scanzano clay is a natural illitic-kaolinitic clay, having liquid limit $w_{L}=58 \%$, plasticity index $P I=30 \%$ and activity $A=0.88$. Samples were reconstituted in a consolidometer under a vertical effective pressure of $100 \mathrm{kPa}$; the main parameters characterising the hydro-electrical behaviour of the clay specimens in the conditions at which they were prepared and used in the tests are reported in Table 1 (data from Musso, 2000; Airoldi et al., 2009; Comina et al., 2010).

A sequence of reconstructed images for Test 2 is reported in Figure 4. Salt appears to spread more in the horizontal direction than in the vertical one. The conductivity increase on the left flank of the specimen, appearing 45 minutes after test beginning, suggests that leakage occurred at the interface between the kaolin and the cell. Leakage was probably due to a weak contact between the soil and the cell wall, which could be linked to both the initial integrity of the kaolin layer and to the shrinkage of the clay caused by chemical consolidation. As a consequence, the saline solute entered the bottom sand layer at first from the sidewall of the specimen ( $t>45 \mathrm{~min}$ ), while the clay layer is interested by transport occurring within the matrix only after 80 minutes. Salt percolation along the boundaries of the clay layer was observed during Test 3 as well.

Despite leakage, globally the clay layers appear to confine and retard the progress of dissolved $\mathrm{NaCl}$. This effect can be observed by comparing the 3D reconstructions of the three tests at the same time $t=90$ min (Figure 5). The flattening of the saline front for Test 2 and 3 (Figure 5-b and 5-c) with respect to the test on the homogeneous sample (Figure 5-a) is evident. The contention effect provided by the barriers is also shown in Figure 6, where images of horizontal sections of the specimens above the barrier $(2.5 \mathrm{~cm}$ from the bottom of the sample) are reported at two different times. A very clear difference in terms of conductivity in the top layer is observed between the homogeneous and two layered samples. 


\section{Discussion and numerical validation of the tests}

The reconstructed electrical conductivity distributions were compared to the results of numerical simulations referring to a homogenous and to a layered sample, to validate tomography results and to assist in understanding physical processes.

In the following, the terminology presented in Bear \& Cheng (2009) is used: the term "advection” is used to indicate the component of solute movement attributed to transport by the flowing water, while "transport" is used to indicate the sum of advection, diffusion and dispersion. Numerical simulations were performed by a finite-element integration of the mass balance equations for the aqueous solution and for the solute. The effect of advection induced by density difference between dense aqueous solution and pure water has been considered, consistently with the evidences presented by Kirino et al. (2009). Density coupling of these equations is also accounted for as proposed by Huyakorn et al. (1987) and Hassanizadeh \& Leijnse (1988).

The finite element solution of the coupled transient problem, determined in terms of the nodal values of the concentration and water pressure, was obtained with a commercial software (Comsol Multiphysics ${ }^{\circledR}$ ). The domain was discretised into tetrahedral elements of eight nodes and the mesh was refined near the salt injection point. The adequateness of Comsol to simulate possible fingering phenomena has been pointed out by Holzbecher (2005, 2009).

Assuming no chemical reactions and constant porosity and degree of saturation, the mass balance equation of the solute can be written as (e.g. Bear and Cheng, 2006):

$$
\phi R_{d} \frac{\partial c}{\partial t}+c \nabla \cdot \mathbf{q}+\mathbf{q} \cdot \nabla c-\phi D \nabla^{2} c=0,
$$


where $\phi=$ porosity, $c=$ solute concentration, $\mathbf{q}=$ specific discharge, $D=$ coefficient of hydrodynamic dispersion (sum of diffusion and mechanical dispersion) and $R_{d}$ is the retardation factor accounting for the mass of solute adsorbed onto the solid grains.

The specific discharge, accounting for density variation, is given by the equation:

$$
\mathbf{q}=-K\left(\nabla h_{0}+\left(\frac{\rho-\rho_{0}}{\rho_{0}}\right) \nabla z\right)
$$

The reference head $h_{0}$ is a function of the pore water pressure $p$, the vertical Cartesian coordinate $z$ and pure water density $\rho_{0}$ :

$$
h_{0}=z+\frac{p}{\rho_{0} g} .
$$

A parameter $a$ is introduced to describe the evolution of water density with concentration, assumed linear as a first approximation:

$\rho=\rho_{0}+a c$

The mass balance for the water can be written as:

$S_{s} \frac{\partial h_{0}}{\partial t}+\phi \frac{a}{\rho_{0}} \frac{\partial c}{\partial t}+\nabla \cdot(\mathbf{q})=0$

where $S_{s}$ is the specific storage.

The whole boundary of the specimen was assumed impermeable to fluxes, except for the salt injection zone where a constant saline concentration, equal to the water solubility of $\mathrm{NaCl}$ (359 g / l), was imposed for times smaller than those of complete dissolution $\left(\mathrm{t}<\mathrm{t}^{*}\right.$ ). Afterwards impermeability to salt was assumed. Over this surface, the atmospheric pressure was imposed to the aqueous phase along the whole simulation.

The electrical conductivity of the interstitial water $\sigma_{w}$ was related to $c$ by relating the specific conductivity of the $\mathrm{NaCl}$ solution to salt concentration (Robinson and Stokes, 1968). 
Given the initial water electrical conductivity, the initial salt concentration was estimated to be $c_{\text {init }}=0.76 \mathrm{~g} / \mathrm{l}$.

Archie's law (Archie, 1942) was then used to link the electrical conductivity of the soil with porosity and electrical conductivity of the pore fluid:

$\sigma=\sigma_{w} \phi^{m}$

The fitting parameter $m$, calculated on the basis of the initial values of $\sigma, \sigma_{w}$ and $\phi$, was imposed equal to $m=1.76$ for the sand and $m=2.0$ for the clay, consistently with the measured values given in Table 1 . The hydraulic conductivity of the clay layer was set as an intermediate value between the one of the two clay samples used in the tests. The complete set of parameters used in the simulations is reported in Table 2.

It was here assumed that mechanical dispersion is limited, so that the diffusion coefficient adopted for the sand is $\mathrm{D}=3 \cdot 10^{-10} \mathrm{~m}^{2} / \mathrm{s}$, in line with literature data (e.g. Freeze and Cherry, 1979). It was as well assumed that the amount of salt adsorbed onto the sand particles is negligible, so that $R_{d}=1$. The trend extracted from the simulation of the physical process (Figure 7a) in the homogeneous sample condition is consistent with experimental observations (Figure 7b). Close to the saline source a peak of the electrical conductivity is recognized. During the homogenization stage, electrical conductivity decreases with a trend toward a common asymptotic value. Both the reconstruction and the simulation predict the absence of the peak for $z$ lower than $1.5 \mathrm{~cm}$. Figure $7 \mathrm{~b}$ shows the experimental values from the ERT reconstructions and a line is depicted to guide the reader to appreciate the evolution.

For the simulations of Test 2 and 3 the presence of an ideal confining barrier has been simulated. To take into account the adsorption phenomena in clayey soils, the apparent diffusion coefficient $D / R_{d}$ was assumed as $1 / 5$ of the sand diffusion coefficient, in line with 
literature data (Shackelford and Daniel, 1991). The simulated clay layer was assumed to be sealed to the cell wall, without allowing any leakage of solute at the interface.

Results obtained with the numerical simulation for two points located in the top and bottom sand layers (points A and B in Figure 2-a and 2-b) are reported in Figure 8 (dotted lines) and compared with the corresponding points for the homogeneous sample (continuous black lines). Since the clay layer is expected to retard the migration of the solute, the model predicts that its presence would cause concentration in point A to increase faster (Figure 8-a) and concentration in point B to increase slower than the homogeneous case (Figure 8-b).

ERT reconstructions referring to the same points are presented in Figure 9. As for point A, the experimental results are qualitatively in good agreement with model predictions (Figure 9a), with Test 2 returning higher concentrations than Test 1 . Nevertheless, retardation does not appear evident in point B, probably because of the clay barrier leakage (Figure 9-b).

To clarify this effect Figure 10 reports experimental conductivity values in two points on the other side of the cell (points A' and B' in Figure 2-b). The barrier effect provided by the clay layer is in this location appreciable also for the lower point (B', Figure 10-b), where Test 2 shows a lower concentration than Test 1 for $\mathrm{t}<600 \mathrm{~min}$. Afterwards, conductivity increases faster in Test 2 than in Test 1, probably because of the leakage identified on the other side of the cell.

The overall behaviour of both the homogeneous and the layered samples was then checked by analysing the evolution of the dissolved salt mass in the pore fluid. This was evaluated by inverting Eq. 6, to infer the local values of $\sigma_{w}$ from ERT reconstructions, and then by relating $\sigma_{w}$ to the $\mathrm{NaCl}$ concentration $c$.

The mass of salt contained in a given volume of soil is then given by volume integration: 
$m=\int c \phi d V \cong \sum_{i=1}^{n} c_{i} \cdot \phi_{i} \cdot \Delta V_{i}$,

where $c_{i}$ is the local estimation of the $\mathrm{NaCl}$ concentration, $n$ the number of elements of the ERT mesh, $\Delta V_{i}$ the volume of the $i^{\text {th }}$ element and $\phi$ the porosity.

The time evolution of the salt mass contained in the upper portion of sand (lying over the clay, or in analogous position for Test 1), and that contained in the bottom one, is drawn in Figure 11. Values are normalised with respect to the total mass of salt that entered the sample during the whole test. The good qualitative agreement between the simulations and the ERT reconstructions further suggests that the amount of salt that leaked was limited.

\section{Conclusions}

Most situations in which monitoring the transport of ionic substances is of critical importance involve three dimensional geometries, due to punctual sources of contamination and soil heterogeneities. The tests presented in this paper were designed to check the capabilities of 3D ERT in investigating transport of contaminants, under well controlled boundary conditions.

ERT located the position of the salt source and reconstructed the shape of the solute plume for both homogeneous and heterogeneous samples. Test results, interpreted in terms of evolution of local electrical conductivity, highlighted leakage due to weak contact between the clay barrier and the cell wall. The detection of these leakages shows the potentiality of 3D ERT in reconstructing complex diffusive flows and preferential flow paths. By integrating electrical conductivity over the volume of the different soil layers the amount of transport occurring across this preferential flow path was however found to be relatively modest.

Numerical simulations of a homogeneous sample and of a layered sample were done to provide an assessment of the consistency of the tomographic reconstruction. Further research developments will concentrate on the possibility of using some of the information provided by 
ERT monitoring as a supporting tool for the calibration and validation of numerical models, possibly leading to a further integration of ERT measurements into procedures of parameter estimation.

\section{ACKNOWLEDGMENTS}

The present work has been partially supported by the research project SoilCam funded by the EU Commission 7th FP and by the Italian National Research Project PRIN 2008B5T829_004. 


\section{REFERENCES}

Airoldi F, Jommi C, Musso G, Paglino E (2009) Influence of calcite on the electrokinetic treatment of a natural clay. Journal of Applied Electrochemistry 39(11):2227-2237

Appelo CAJ, Postma D (1993) Geochemistry, groundwater and pollution. Balkema, Rotterdam, The Netherlands

Archie GE (1942) The electrical resistivity log as an aid to determining some reservoir characteristics. Trans AIME 146:54-63

Bear J, Cheng AHD (2009) Modeling Groundwater Flow and Contaminant Transport. Springer

Binley A, Henry-Poulter S, Shaw B (1996) Examination of solute transport in an undisturbed soil column using electrical resistance tomography. Water Resources Research 32(4):763-769 Borsic A, Comina C, Foti S, Lancellotta R, Musso G (2005) Imaging heterogeneities with electrical impedance tomography: laboratory results. Géotechnique 55(7):539-547

Comina C, Foti S, Lancellotta R, Musso G, Borsic A (2005) Imaging heterogeneities and diffusion in sand samples. In: Proceedings of the 11th International Conference of the International Association of Computer Methods and Advances in Geomechanics IACMAG. Torino, vol.2 pp 27-34.

Comina C, Foti S, Musso G, Romero E (2008) EIT oedometer - an advanced cell to monitor spatial and time variability in soil. Geotechnical Testing Journal ASTM 31(5):404-412.

Comina C, Cosentini RM, Foti S, Musso G (2010). Electrical tomography as laboratory monitoring tool. Rivista Italiana di Geotecnica 44:15-26.

Cosentini RM, Della Vecchia G, Foti S, Musso G (2012) Estimation of the hydraulic parameters of unsaturated samples by electrical resistivity tomography. Géotechnique. in print Damasceno VM, Fratta D, Bosscher PJ, (2009) Development and validation of a low-cost electrical tomographer for soil process monitoring. Canadian Geotechnical Journal 46:842854

Freeze A R, Cherry JA (1979). Groundwater. Prentice Hall.

Hassanizadeh SM, Leijnse T (1988) On the modelling of brine transport in porous media. Water Resources Research 24(3):321-330 
Huyakorn PS, Andersen PF, Mercer JW, White HO (1987) Saltwater intrusion in aquifers: development and testing of a three.dimensional finite element model. Water Resources Research 23(2):293-312

Holzbecher E (2005) FEMLAB performance on 2D porous media variable density benchmarks. In: Proceedings of FEMLAB Konferenz. pp 203-208

Holzbecher E (2009) Modeling of viscous fingering. In: Proceedings of the 2009 COMSOL Conference. Boston

Jiao CY, Holtz H (2004) An experimental study of miscible displacements in porous media with variation of fluid density and viscosity. Transport in Porous Media 54: 125-144

Kemna A, Vanderborght J, Kulessa B, Vereecken H (2002) Imaging and characterisation of subsurface solute transport using electrical resistivity tomography (ERT) and equivalent transport models. Journal of Hydrology 267:125-146

Kirino Y, Yokoyama T, Hirono T, Nakajima T, Nakashima S (2009) Effect of density-driven flowon the through-diffusion experiment. Journal of Contaminant Hydrology 106:166-172

Koestel J, Kemna A, Javaux M, Binley A, Vereecken H (2008) Quantitative imaging of solute transport in an unsaturated and undisturbed soil monolith with 3-D ERT and TDR. Water Resources Research 44 (W12411) doi:10.1029/2007WR006755.

Liu HH (1996) A criterion for gravitational instability in miscible dense plumes. Journal of Contaminant Hydrology 23:233-243

Musso G (2000) Electrokinetic phenomena in soils. PhD Thesis, Politecnico di Torino

Müller K, Vanderborght J, Englert A, Kemna A, Huisman JA, Rings J, Vereecken H (2010) Imaging and characterization of solute transport during two tracer tests in a shallow aquifer using electrical resistivity tomography and multilevel groundwater samplers. Water Resources Research 46(W03502) doi:10.1029/2008WR007595

Reynolds JM (1997) An Introduction to Applied Environmental Geophysics. John Wiley \& Sons, Chichester, UK

Robinson RA, Stokes RH (1968) Electrolyte solutions. Buttherworths, London.

Santamarina JC in collaboration with Klein KA, Fam MA (2001) Soils and Waves. John Wiley and Sons, New York.

Shackelford CD, Daniel ED (1991) Diffusion in saturated soil. I: Background. Journal of Geotechnical Engineering 117(3):467-484. 
Van Dam RL, Simmons CT, Hyndman DW, Wood WW (2009) Natural free convection in porous media: first field documentation in groundwater. Geophysical Research Letters 36(L11403) do1:10.1029/2008GL036906.

\section{FIGURE CAPTIONS}

Figure 1. Picture of the EIT-edometer cell

Figure 2. Experimental setup for the dissolution and transport tests: (a) homogeneous sample, (b) heterogeneous sample.

Figure 3. 3D diffusion test on homogeneous sand sample (Test 1): images of the solute plume at different times.

Figure 4. 3D diffusion test on layered sample (Test 2): images of the solute plume at different times.

Figure 5. Images of the solute plume at time $t=90 \mathrm{~min}$ from the beginning of the test: a) Test 1; b) Test 2; c) Test 3.

Figure 6. Reconstructed electrical conductivity along horizontal sections at $2.5 \mathrm{~cm}$ from the base of the samples ( $t=45 \mathrm{~min}$ and $t=90 \mathrm{~min}$ from the beginning of the diffusion):

a) Test 1; b) Test 2; c) Test 3.

Figure 7. Electrical conductivity breakthrough curves for the homogeneous sample at different heights along the vertical line passing through the $\mathrm{NaCl}$ source: a) Numerical simulation; b) Experimental data from ERT reconstructions of Test 1.

Figure 8. Comparison of electrical conductivity breakthrough curves at point A (fig. 7a) and B (fig. 7b) predicted by the numerical simulation for the homogeneous sample and for the ideal (perfect contact) layered sample. The retardation effect provided by the clay layer can be appreciated for both points. 
Figure 9. Comparison of electrical conductivity breakthrough curves at point A (fig. 8a) and B (fig. 8b) as given by ERT reconstructions for Test 1 and Test 2. The consequences of leakage during Test 2 can be appreciated especially for point B.

Figure 10. Electrical conductivity breakthrough curves at point A' (fig. 9a) and B' (fig. 9b) as given by ERT reconstructions for Test 1 and Test 2 .

Figure 11. Evolution with time of normalized salt mass distribution in Test 1 and Test 2: a) numerical simulations; b) ERT reconstructions . 
FIGURES

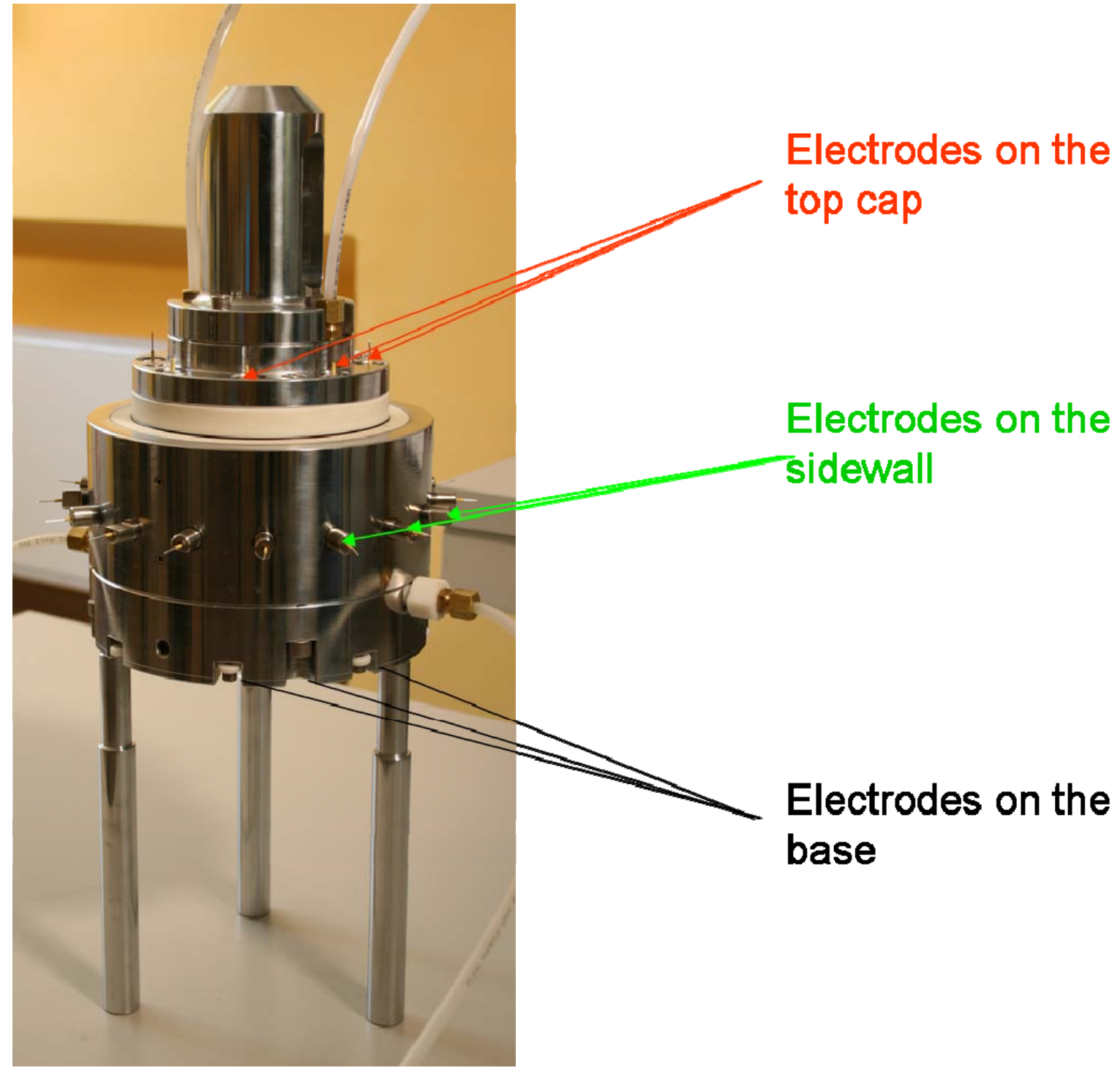

Figure 1 

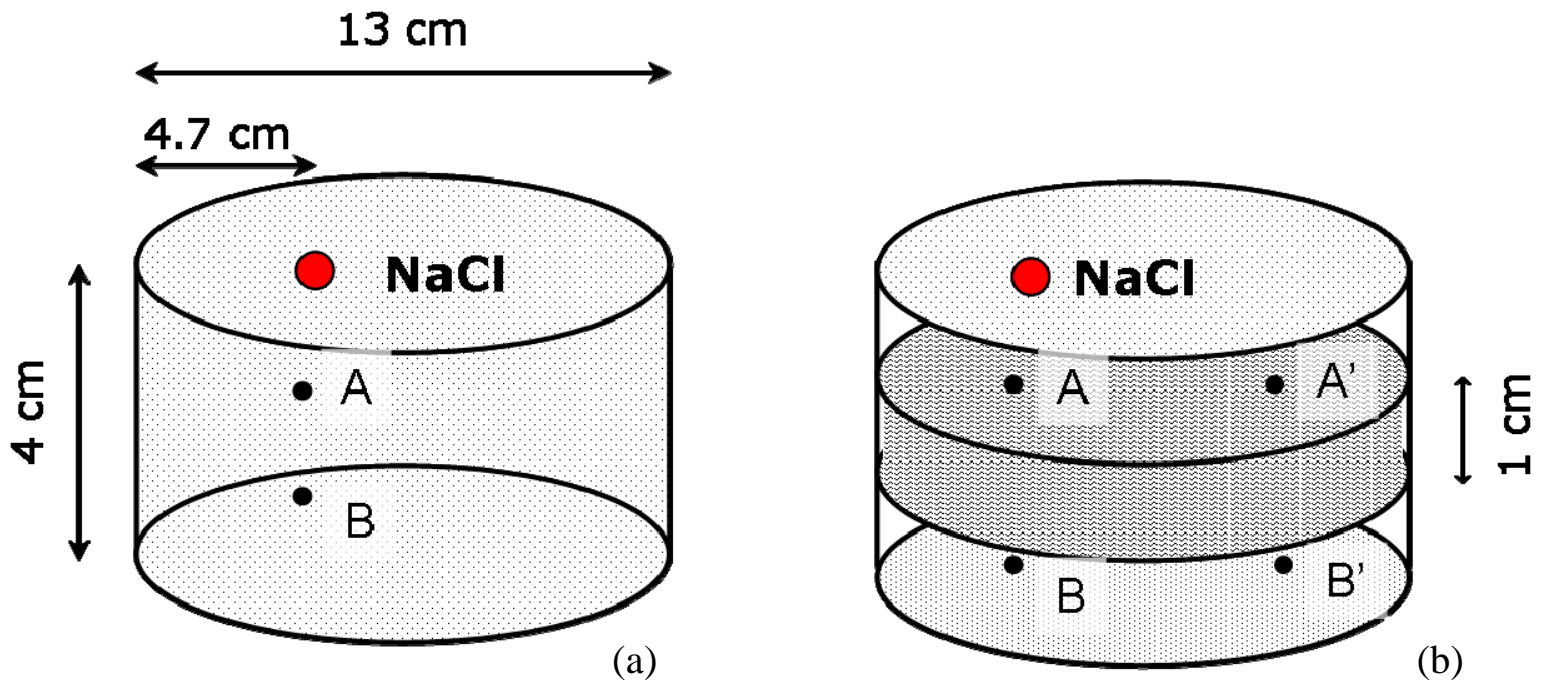

$\$$ Sand

Clay

Figure 2 


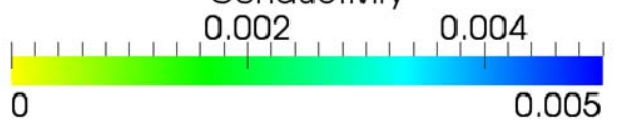

$$
\mathrm{T}=20 \mathrm{~min}
$$

$$
\mathrm{T}=60 \mathrm{~min}
$$
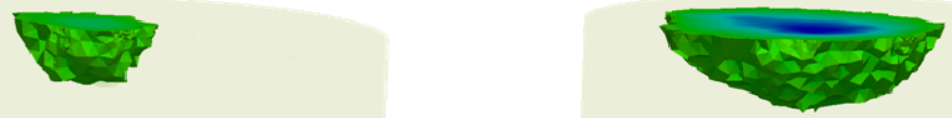

$\mathrm{T}=\mathbf{3 0} \mathrm{min}$

$\mathrm{T}=80 \mathrm{~min}$
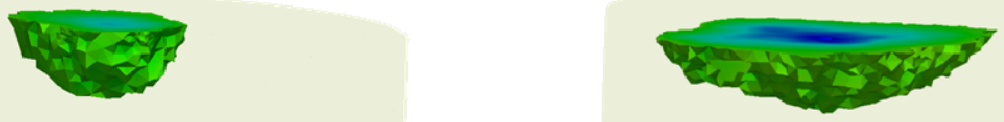

$\mathrm{T}=45 \mathrm{~min}$

$\mathrm{T}=90 \mathrm{~min}$
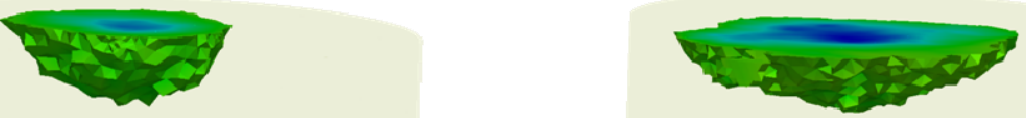

Figure 3 


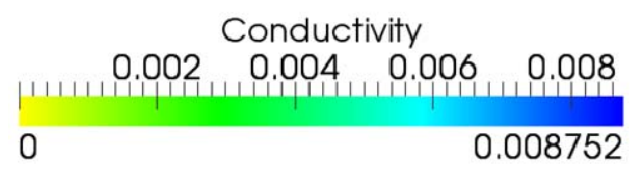

$$
\mathrm{T}=\mathbf{2 0} \mathrm{min}
$$

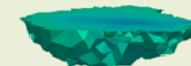

$$
\mathrm{T}=\mathbf{3 0} \mathrm{min}
$$

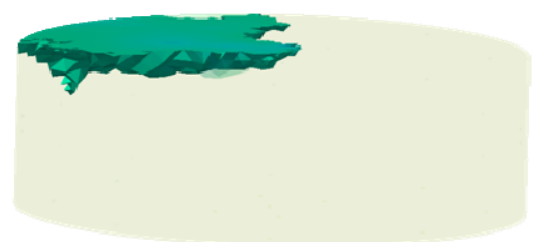

$$
\mathrm{T}=45 \mathrm{~min}
$$

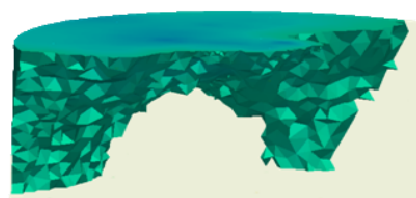

$\mathrm{T}=60 \mathrm{~min}$

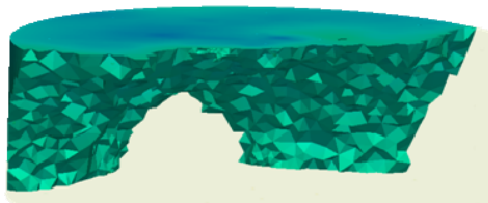

$$
\mathrm{T}=80 \mathrm{~min}
$$

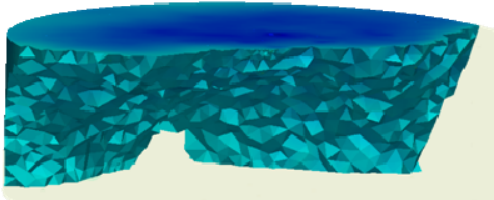

$$
\mathrm{T}=90 \mathrm{~min}
$$

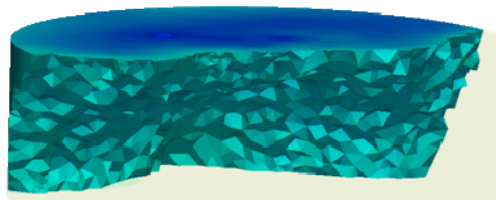

Figure 4 

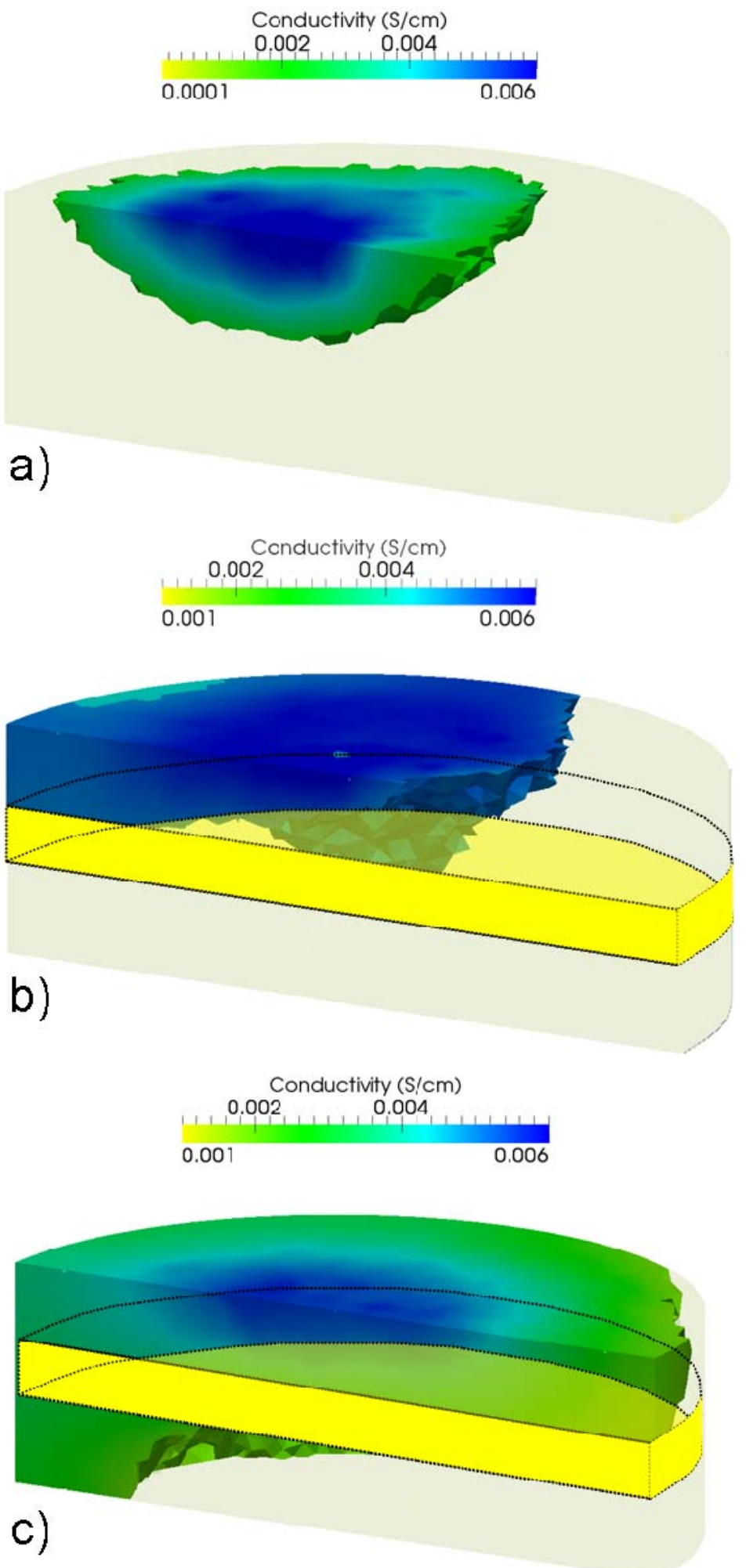

Figure 5 


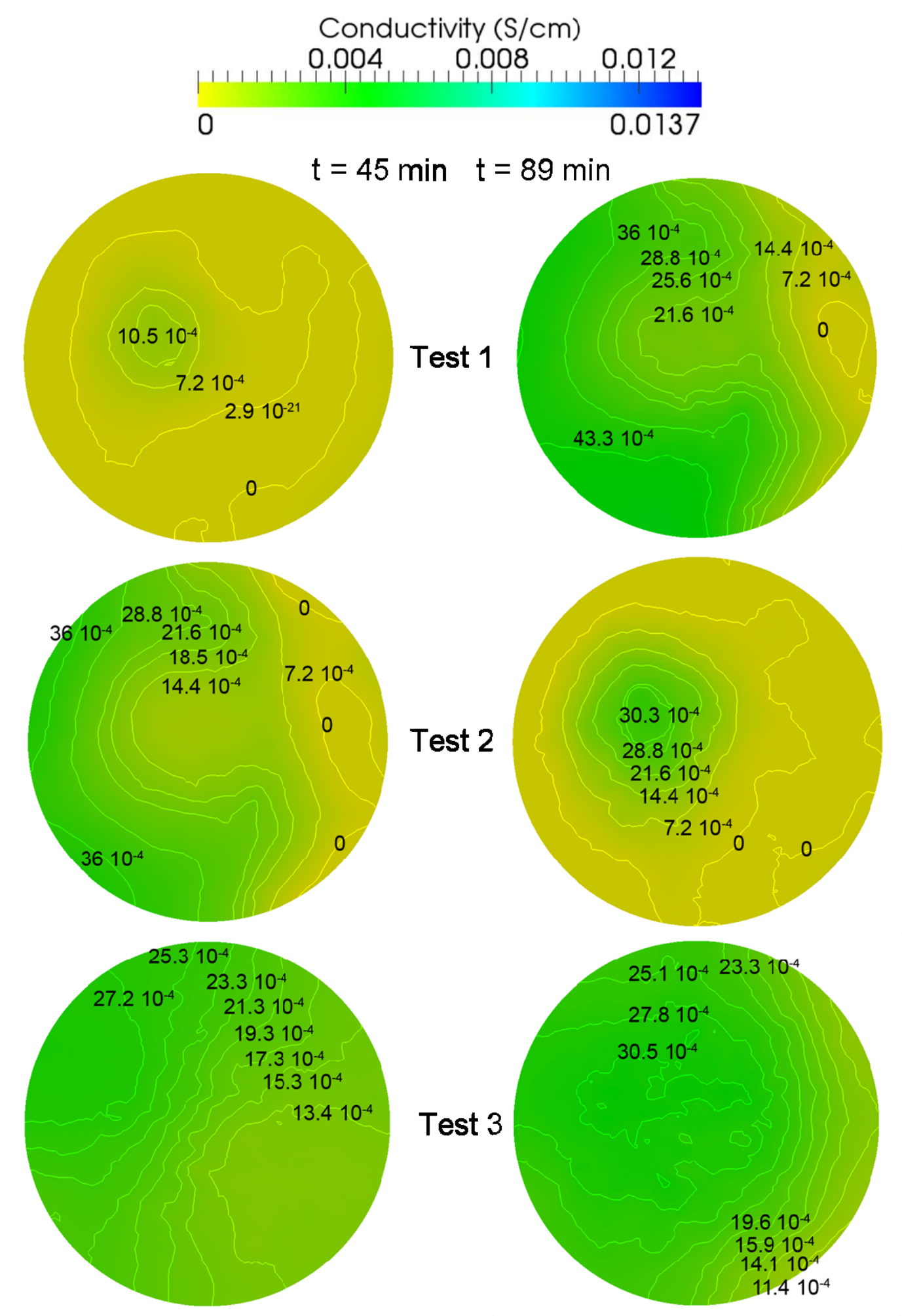

Figure 6 


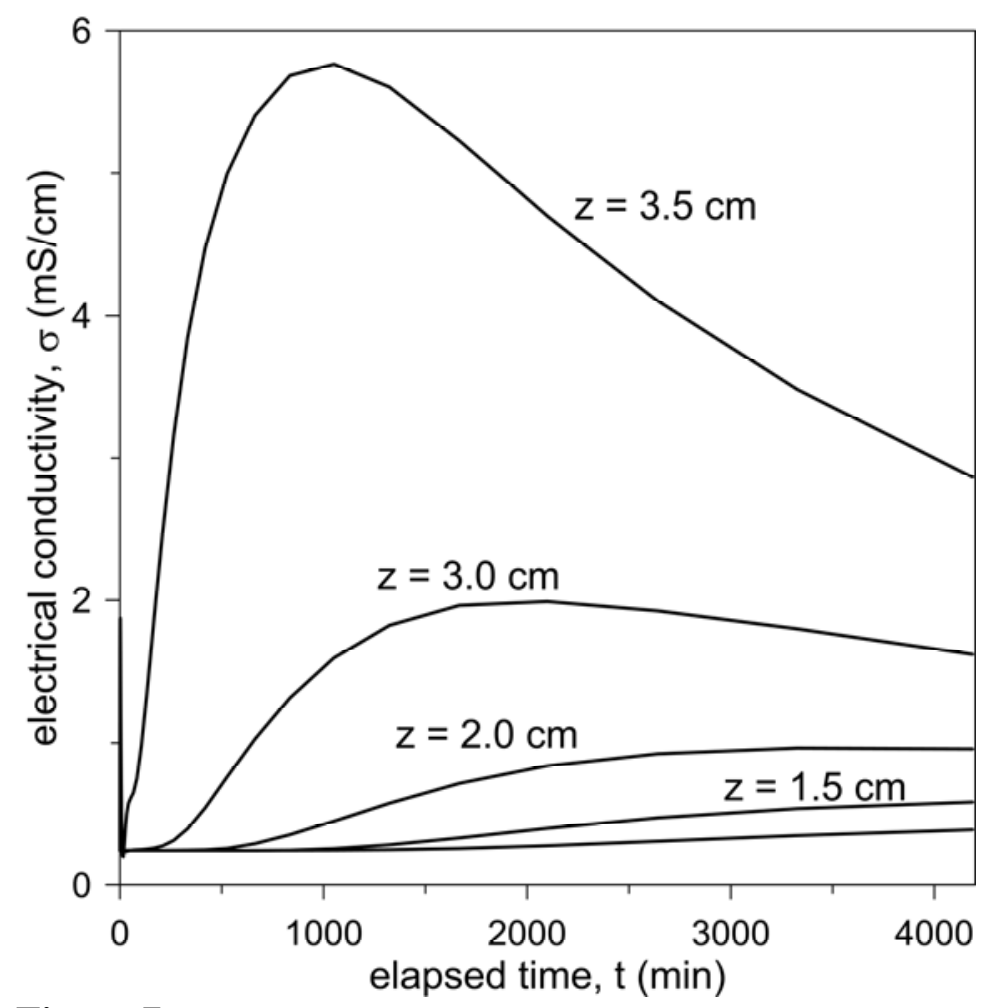

Figure 7a

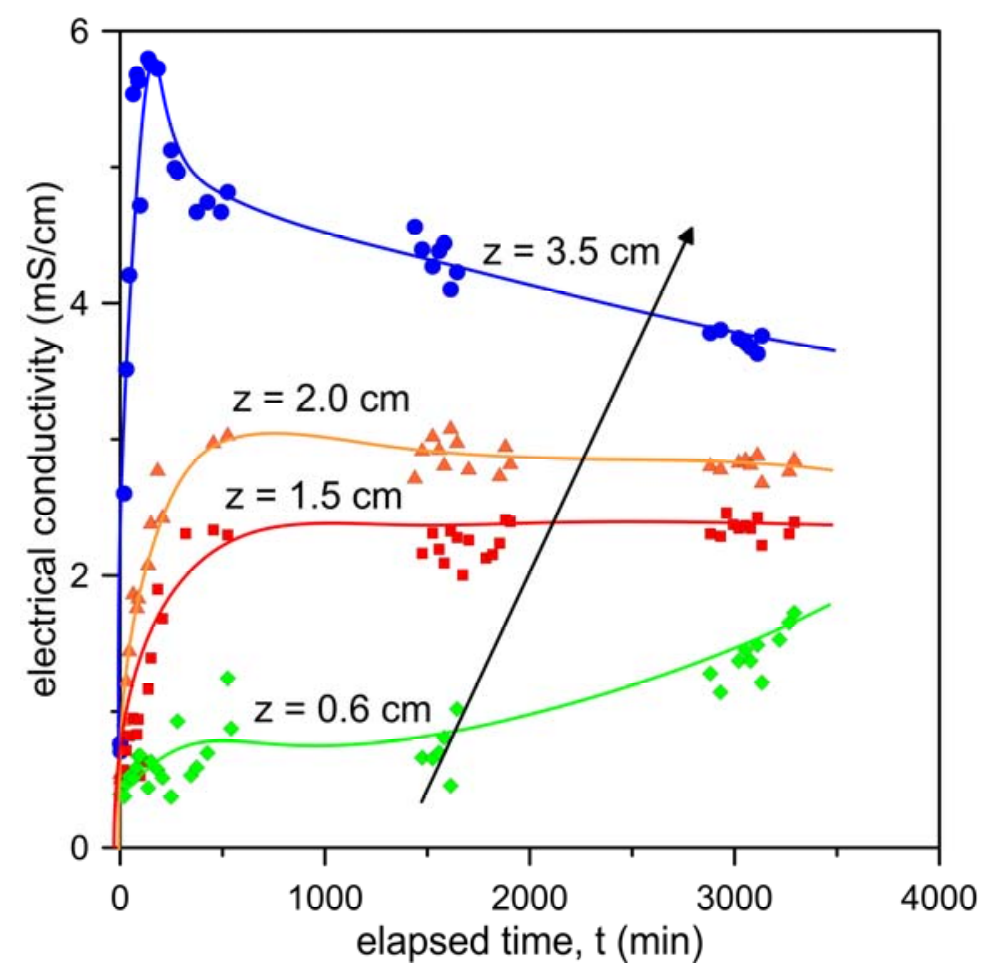

Figure 7b 

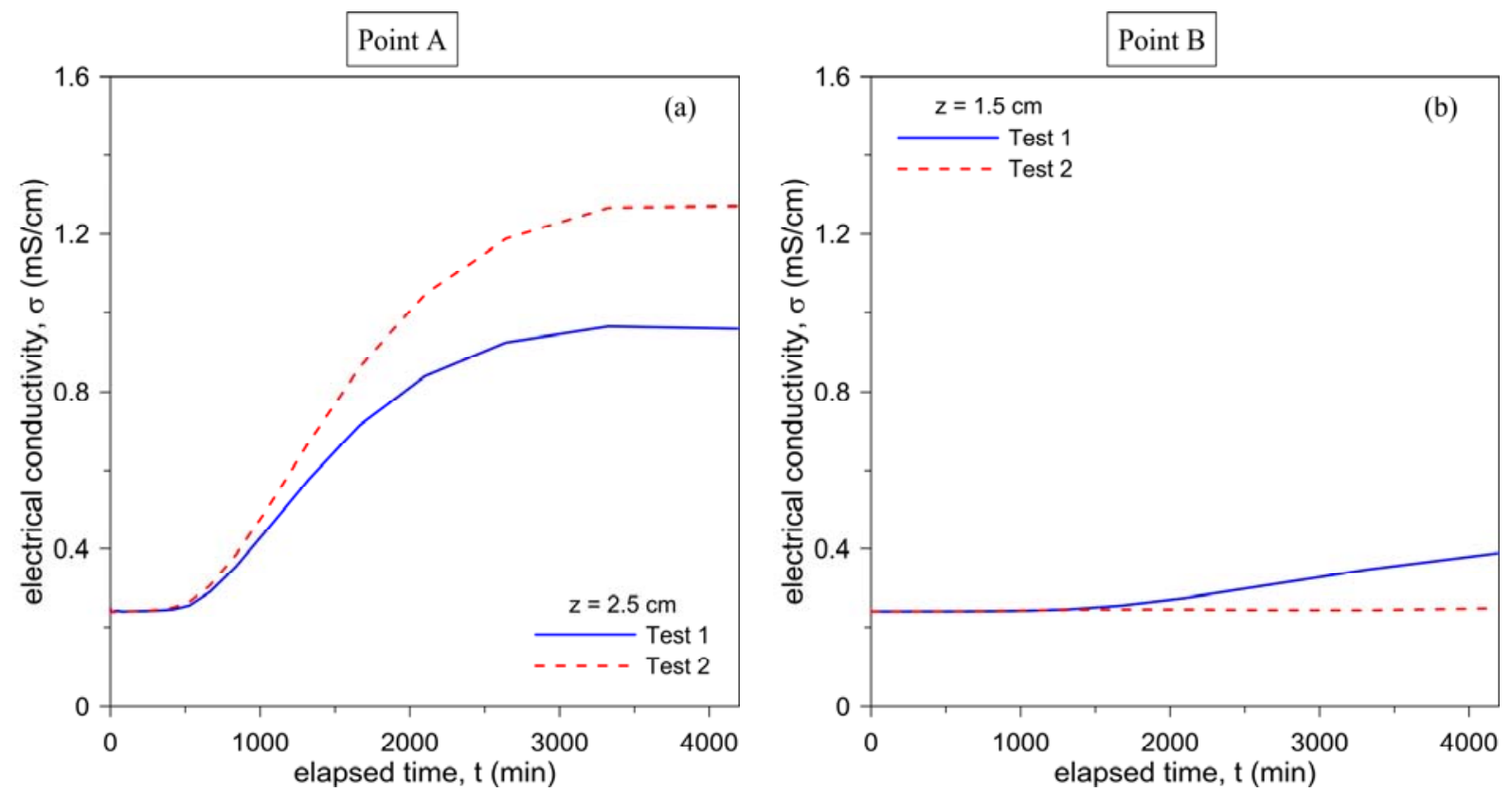

Figure 8
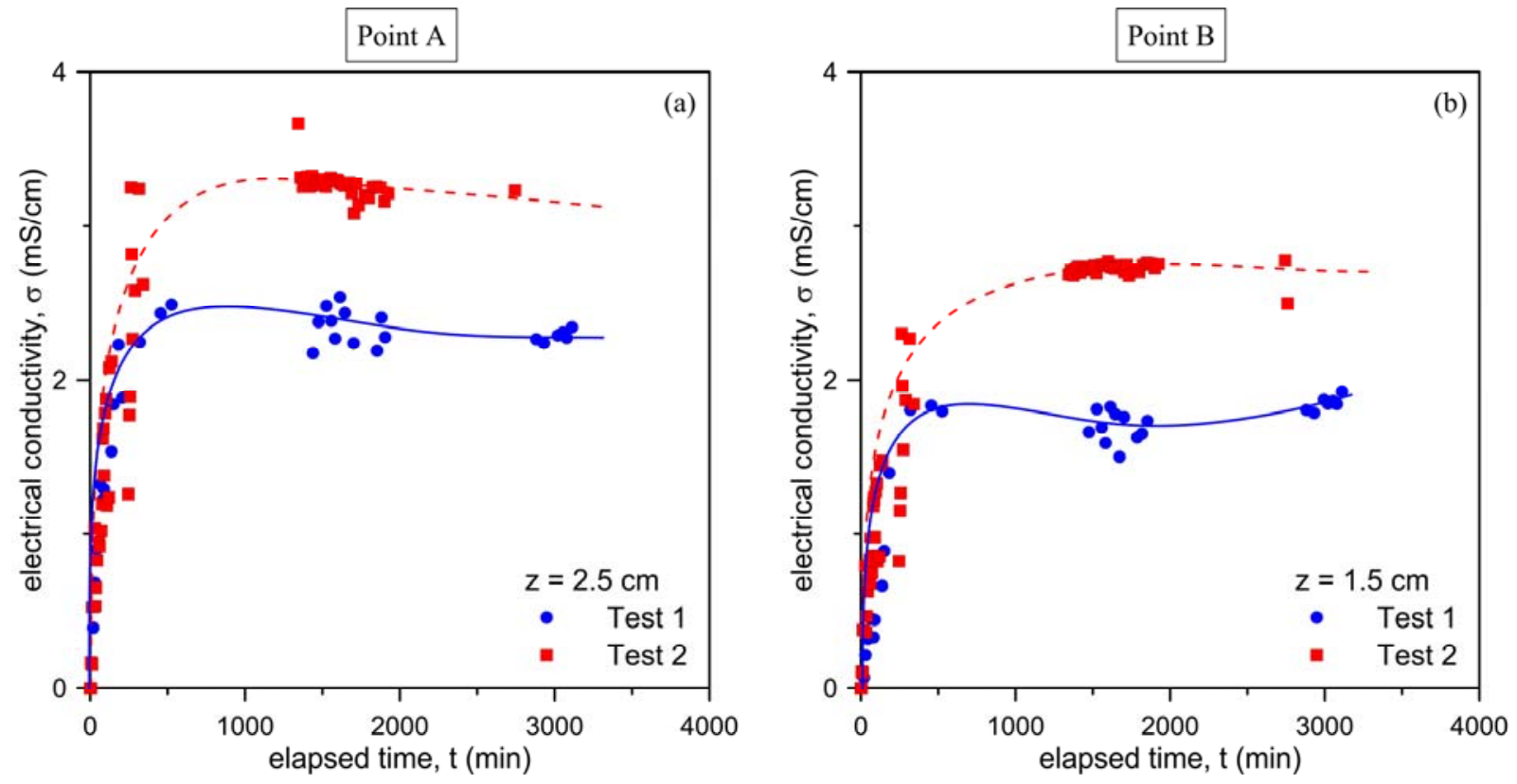

Figure 9 

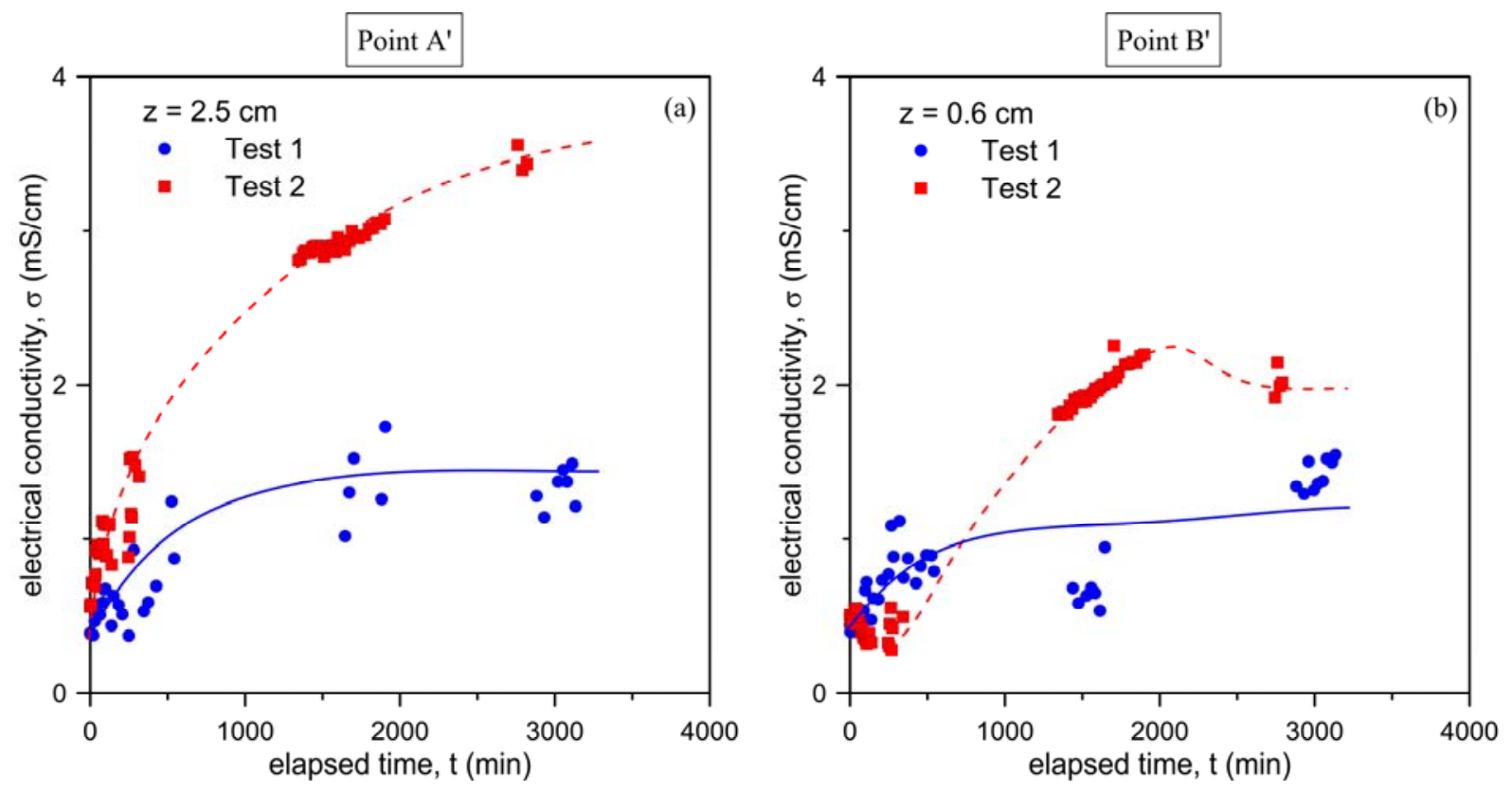

Figure 10
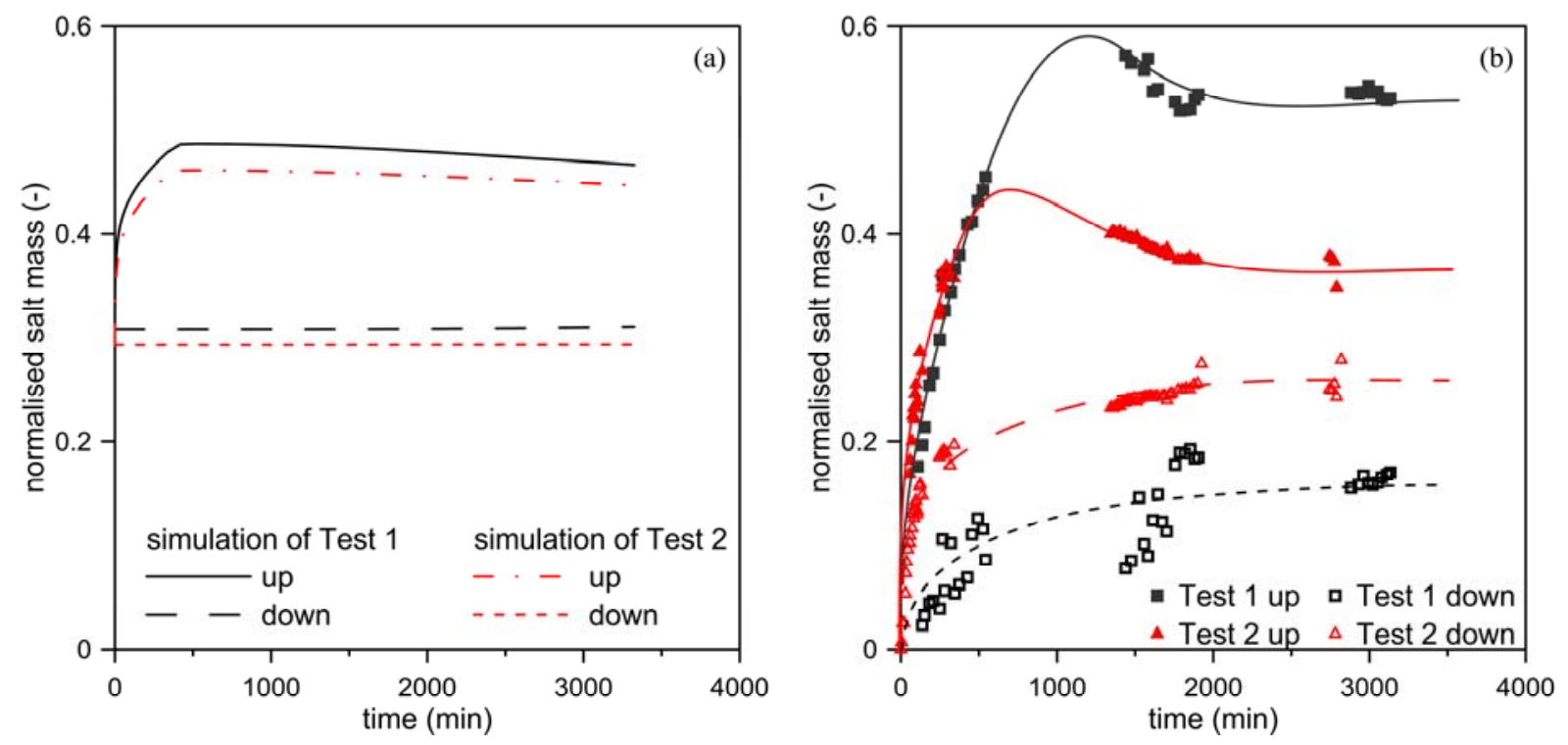

Figure 11 
TABLES

\begin{tabular}{|l|c|c|}
\hline & Kaolin & Scanzano Clay \\
\hline Porosity, $\mathrm{n}(-)$ & 0.5 & 0.49 \\
\hline $\begin{array}{l}\text { Hydraulic conductivity, } \\
\mathrm{K}_{\mathrm{w}}(\mathrm{m} / \mathrm{s})\end{array}$ & $410^{-9}$ & $3.610^{-10}$ \\
\hline $\begin{array}{l}\text { Electrical conductivity, } \\
\sigma(\mathrm{S} / \mathrm{m})\end{array}$ & 0.10 & 0.23 \\
\hline $\begin{array}{l}\text { Archie's porosity exponent, } \\
\mathrm{m}(--)\end{array}$ & 2.00 & 1.91 \\
\hline $\begin{array}{l}\text { Electroosmotic conductivity, } \\
\mathrm{K}_{\mathrm{eo}}\left(\mathrm{m}^{2} / \mathrm{V} \mathrm{s}\right)\end{array}$ & $810^{-9}$ & $210^{-9}$ \\
\hline
\end{tabular}

Table 1. Hydro-electrical characteristics of the clay specimens used for the tests.

\begin{tabular}{|c|c|c|c|c|c|c|c|c|c|}
\hline \multicolumn{4}{|c|}{ Sand } & \multicolumn{4}{|c|}{ Clay } & & \\
\hline $\begin{array}{c}\phi \\
(-)\end{array}$ & $\begin{array}{c}K \\
(\mathrm{~m} / \mathrm{s})\end{array}$ & $\begin{array}{l}D / R d \\
\left(\mathrm{~m}^{2} / \mathrm{s}\right)\end{array}$ & $\begin{array}{l}m \\
(-)\end{array}$ & $\begin{array}{c}\phi \\
(-)\end{array}$ & $\begin{array}{c}K \\
(\mathrm{~m} / \mathrm{s})\end{array}$ & $\begin{array}{l}D / R d \\
\left(\mathrm{~m}^{2} / \mathrm{s}\right)\end{array}$ & $\begin{array}{l}m \\
(-)\end{array}$ & $\begin{array}{c}\rho_{0} \\
(\mathrm{~kg} / \mathrm{m} 3)\end{array}$ & $\begin{array}{c}a \\
(-)\end{array}$ \\
\hline 0.4 & $1 \cdot 10^{-6}$ & $3 \cdot 10^{-10}$ & 1.8 & 0.5 & $1 \cdot 10^{-9}$ & $6 \cdot 10^{-11}$ & 2.0 & $9.96 \cdot 10^{2}$ & 0.820 \\
\hline
\end{tabular}

Table 2. Parameters used in the numerical simulations 